\section{Seeing is Belizing}

$\mathrm{O}$ $\mathrm{n}$ a quiet Sunday morning in the emergency unit at the Belmopan Hospital, an electronic message on the Belize Health Information System (BHIS) flashed an alert to the doctor and nurses on duty: A patient with severe stab wounds was on his way by ambulance from the San Ignacio polyclinic near the border with Guatemala, about 50 kilometres to the west.

According to the clinical notes on the BHIS, the patient was in critical condition with a suspected punctured lung.

The senior nurse took a minute to confer with the doctor on duty, Mercedes Ken. A bed was prepared. Ken checked the patient information accompanying the electronic message on the BHIS and read through the clinical notes explaining the treatment course followed by the intake doctor in San Ignacio.

So, when the patient was wheeled off the ambulance, the extent of his wounds was no surprise to Ken. What was a surprise was that with two dozen stab wounds peppered around his spine, he was still conscious enough to answer questions relating to adverse drug reactions. But thanks to the BHIS information, Ken would have known the answers anyway.

Using the BHIS, she had already sent his file to a lung specialist. "The file has already been reviewed by quite a few physicians by now, in fact," she revealed. "We can move clinical information throughout Belize instantaneously. And frankly, this patient will be far more likely to survive because of that."

In a small, Central American state ranked 78th on the United Nations' Human Development Index, the stateof-the-art-BHIS is no small wonder. Built around software developed by a small New Brunswick-based company called Accesstec, the BHIS has stitched 44 clinics and hospitals together within an electronic infostructure now serving most of Belize's 301000 people even those living on tiny islands far offshore in the Carribbean.

Government health expenditures for citizens of Belize are about one fifteenth that of Canada. But even so, according to the recently released WHO ATLAS eHealth country profiles, Belize has

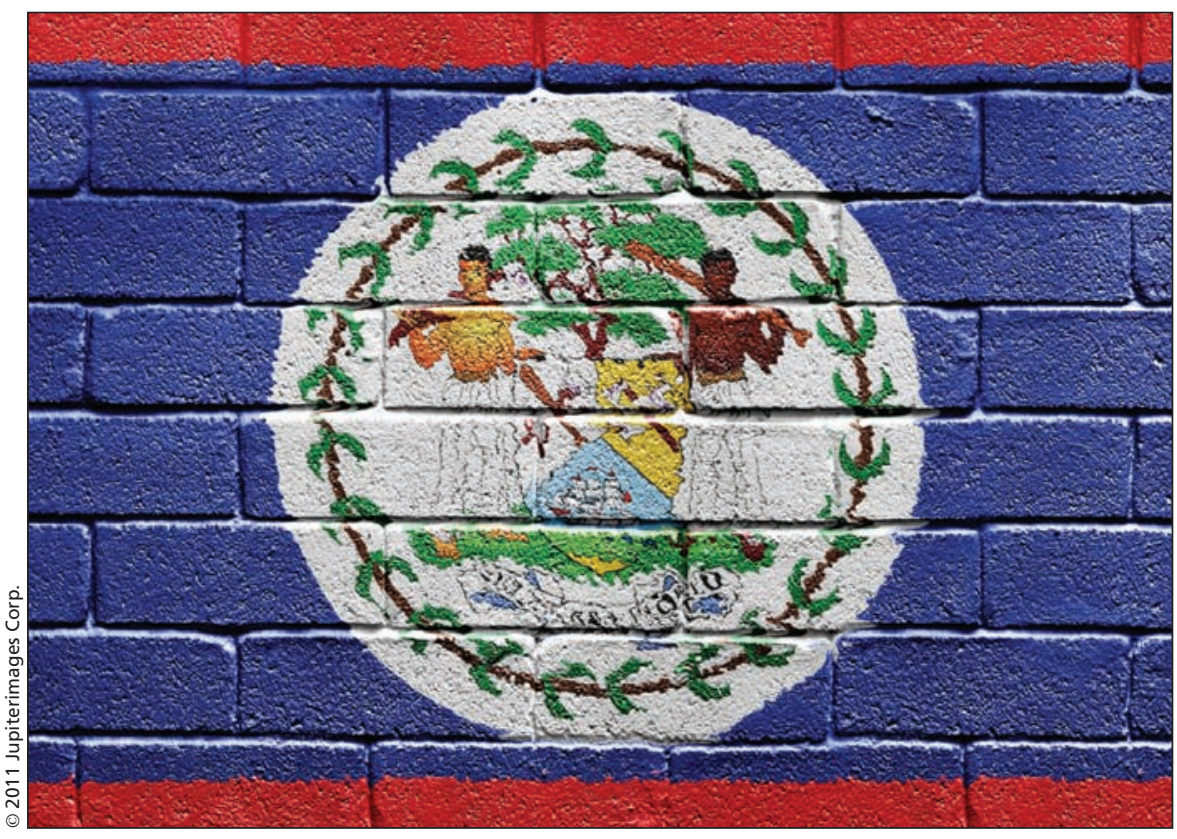

A global "landscape analysis" of health information systems in developing countries commissioned by the Bill \& Linda Gates Foundation in 2010 praised Belize's achievement as world-leading.

made remarkable progress on ehealth with public investment in a full suite of ehealth tools including information technology hardware and software, ehealth pilot projects, skills training, ongoing system support and ehealth scholarships (www.who.int/goe/publications/ehealth _series_vol1/en/index.html).

A global "landscape analysis" of health information systems in developing countries commissioned by the Bill \& Linda Gates Foundation in 2010 praised Belize's achievement as worldleading: "Although Belize had a very rudimentary, paper-based health information system as recently as 2004, today it has perhaps the most comprehensive nationwide HIS [health information system] in the world," the analysis concluded (www.vitalwave consulting.com/publications/pdf/Vital $\% 20$ Wave $\% 20$ Consulting $\% 20$ Gates $\%$ 20Foundation $\% 20 \mathrm{HIS} \% 20$ Analysis\% 202009.pdf).

Physicians in Belize credit Peter Allen, CEO of the Ministry of Health, with building the BHIS. But the toughminded Scottish accountant with a doctorate in public health credits the country's political leadership. "There is no way we could have done this without top-level political commitment every step of the way," adds Allen, who says the BHIS yields impressive improve- ments in patient outcomes, especially among the substantial community of people living with AIDS. Maternalchild transmission of HIV has dropped from about $40 \%$ to about $5 \%$, he notes.

In a review of the BHIS by the WHO's Health Metrics Network, Belize's government described the system as "key" to national development. The government's rationale? "Given our fiscal constraints it is imperative that a national HIS is in place to provide the information needed to make evidence based decisions that will result in desired health outcomes and leverage our scarce resources" (www.who.int /healthmetrics/library/countries/HMN _BLZ_Assess_Final_2008_06_en.pdf).

As a result, the tiny, impoverished nation has managed to build something that Canada - despite 17 years of planning and at least \$4-billion in government spending — still lacks: a working national health infostructure that reaches almost every patient in the country.

Not surprisingly, the two Canadians who fashioned the BHIS - Halifax, Nova Scotia-based neonatalist and software engineer Michael Graven, and St. John, New Brunswick-based systems engineer Tristan Rutter - see Belize's achievement as something Canada's eHealth mandarins might want to emulate. 
The system was designed with input from clinicians at every step in the process, they say. "If you can capture the clinical encounter, you've got all the basics," says Rutter. "An electronic health record is simply a transaction management instrument. The BHIS is an encounter-centric health information system that can aggregate data at any level."

It's even hurricane-proof, he boasts.

Graven, who taught Allen at the University of South Florida, sees health information technology as being as transformative as the development of vaccines and antibiotics.

In Belize, the BHIS has propelled enormous advances in the management of chronic conditions such as hypertension and diabetes, he says. Hospitalizations for people over 65 have plummeted $25 \%$.

An assessment by the Caribbean Community Secretariat in 2010 estimated that BHIS reduced national health budget costs by as much as $3 \%$, and adverse drug reactions by $90 \%$. Allen says BHIS repaid its modest cost through efficiencies within about six months.

Although Canada Health Infoway has long contended that building a national electronic record system is expensive and complicated, Graven and Rutter say it need not be so. BHIS is largely underpinned with free, "open source" software (www.cmaj.ca/cgi/doi /10.1503/cmaj.109-3744). Accesstec's innovations are licensed to Belize in perpetuity without ongoing fees. The system is maintained and expanded by government employees, rather than high-priced consultants.

Similar proven solutions have been pioneered and are freely available in Canada, Rutter and Graven note. But Canada has "invested in multiple, expensively licensed software systems, many of which cannot be supported," Graven fumes. "The whole thing got hijacked. Almost all of the money is going to big industry players. I would recommend we develop a single system for Canada, and Canada should own it. Let's do it the way Belize did it. After all, they got that idea mostly from us." - Paul Christopher Webster, Belmopan, Belize

CMAJ 2011. DOI:10.1503/cmaj.109-3782

\section{More news at www.cmaj.ca}

Free "global university" launched: Organizers of a free "global university" plan to use the Internet to enable people in the developing world who don't readily have access to medical education to become physicians. — David Yin, Ottawa, Ont.

Rwanda struggles to treat its burden of blindness: The Rwandan government has unveiled a national plan to provide eye care for the tens of thousands of citizens who could have their eyesight substantially improved with appropriate care. - Elyse Skura, Kigali, Rwanda

Clinical practice guidelines as marketing tools: Little scrutiny has been applied to recommendations made in industry-funded clinical guidelines, which are used extensively by clinicians and therefore have a direct impact on patient care. - Roger Collier, CMAJ

Experts call for national immunization registry, coordinated schedules: The Canadian Public Health Association and leading pediatricians and immunologists are calling for a national immunization registry and harmonized vaccination schedules. - Laura Eggertson, Ottawa, Ont.

Swiss medical technology industry gobbling up market share: Switzerland is bulling its way onto the global medical technology market through a combination of government technology development programs, a talented labour pool, a supportive academic community and favorable tax rates. - Paul McLaughlin, Lausanne, Switzerland

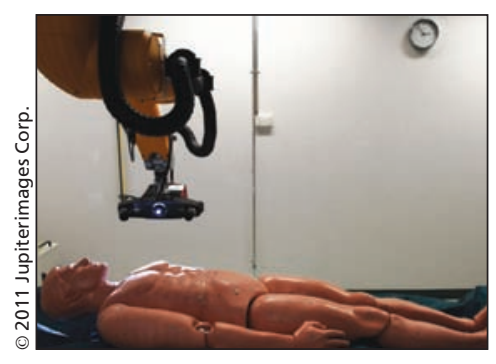

Pocket-sized help for people with dementia: A simple means of informing people that someone is suffering from dementia has become an invaluable asset in several European nations. - Roger Collier, CMAJ

Clinical guideline writers often conflicted: Rarely a week goes by without a medical society releasing a new or updated set of clinical practice guidelines. It's altogether common that the authors have some form of relationship with industry. - Roger Collier, CMAJ

The therapeutic value of hyper-suggestibility: Attitudes toward the use of hypnosis in medicare are slowly shifting as a result of the increased volume of peer-reviewed studies demonstrating hypnotherapy's effectiveness as a hospital or clinic-based treatment. - Wendy Glauser, Toronto, Ont.

Rescuing doctors in distress: Switzerland has developed a program to "rescue" physicians with professional and personal problems through crisis intervention, mentoring and coaching. - Claire Hegenbarth MD, Berlin, Germany

Milk sharing: boon or biohazard?: More than two decades after fears of HIV transmission forced the closure of all but one of Canada's 23 milk banks, regulators, medical professionals and mothers remain divided on the safety of sharing breast milk. — Lauren Vogel, CMAJ

CMAJ 2011. DOI:10.1503/cmaj.109-3789 